\title{
A SURVEY OF BLASTING ACTIVITY IN THE UNITED STATES
}

\author{
By Paul G. Richards, Douglas A. Anderson, and David W. Simpson
}

\begin{abstract}
Statistical information on chemical explosions is needed in seismology, to evaluate the practical difficulties in identifying this very common type of seismic source from other seismic sources such as small earthquakes and small nuclear explosions.

We have obtained data on blasting activity from three different sources: (1) overview information from the U.S. Bureau of Mines (USBM) on the total amount of chemical explosives used in the United States during 1987, with breakdowns into different explosive types, and usage by different states; (2) overview information from the Mine Safety and Health Administration (MSHA) on the numbers of mines, of different types, in the United States; and (3) detailed information from a private company (Vibra-Tech Engineers, Inc.) on total shot size and size of charge per delay for 20,813 blasts carried out in 1987 at 532 locations.

Our procedure has been to extrapolate the detailed information contained in the 1987 Vibra-Tech data for a limited number of states and thus to obtain estimates for the whole country on numbers of shots and their size distribution. The extrapolation is constrained by the data from USBM (numbers of shots, sizes) and the MSHA (locations). Blasting activity does not fluctuate greatly from year to year and 1987 was representative of current practice.

We find that about 2.2 million metric tons of chemical explosive are used annually in the continental U.S., principally in mining for coal and metal ores. On a typical work day, there are roughly 30 explosions greater than 50 tons, including about one greater than 200 tons. There was one industrial explosion in 1987 at about 1400 tons. For shots between 1 ton and 100 tons, the cumulative distribution has a $b$-value near unity; that is, if $N$ is the number of shots (per year) greater than or equal to $w$ tons,
\end{abstract}

$$
N \propto 10^{-b \log W}=W^{-b}
$$

with b roughly equal to 1 . This result is similar to the size distribution of earthquakes greater than magnitude $m_{b}$,

$$
N \propto 10^{-b m_{b}} .
$$

Almost all chemical explosions above 1 ton are ripple-fired. The typical shot uses 20 to $\mathbf{5 0}$ separate delays.

\section{INTRODUCTION}

A general reason for seismologists to be interested in blasting activity is that, in many parts of the world, there are far more seismograms obtained from chemical explosions than there are from naturally occurring earthquakes. For purposes of studying Earth structure, explosion seismograms can be even more useful than earthquake seismograms, not only because of the better areal coverage, but also because it is often possible to get precise information on the source location and source origin time.

A specialized but very important reason to study blasting is in the context of discriminating nuclear explosions from other seismic sources. If the source was 
obviously large, so that if it were an explosion it would have to be greater than 1 kiloton, then it is usually possible to identify the source quite easily from analysis of seismic signals (see, for example, Taylor et al., 1989; Richards and Zavales, 1990). For smaller events the discrimination problem gets harder, because there are fewer signals with adequate signal-to-noise ratio, and also because the rate of occurrence increases. The statistics of this increase have been documented extensively for earthquakes, but the statistics for chemical explosions have not been available and were a goal of the present study.

The importance of chemical explosions in determining U.S. capability to discriminate nuclear explosions in the former U.S.S.R. was summarized by the Office of Technology Assessment (U.S. Congress, 1988) as follows:

... there appears to be agreement that, with internal stations that detect down to $m_{b}$ 2.0-2.5, identification can be accomplished in the U.S.S.R. down to at least as low as $m_{b} 3.5$. This cautious assessment is currently set by the uncertainty associated with identifying routine chemical explosions that occur below this level...

The conclusion here is that chemical explosions are the limiting factor in setting the identification level for underground nuclear explosions.

The blasting agent most often used for industrial explosions is known as ANFO (an acronym for ammonium nitrate and fuel oil). ANFO delivers about $90 \%$ of the energy per unit mass obtainable with TNT, for which the term "kiloton" was originally defined. The modern definition of a kiloton, as an energy measure of nuclear explosion yield, is $10^{12}$ calories. Where it is necessary in this paper to convert between pounds (lb) and tons, we shall use the metric ton (containing about $2200 \mathrm{lb}$ ).

When we started in the mid-1980s to make informal inquiries about the extent of chemical explosion activity in the United States, we were given much anecdotal information on shot sizes and explosion practice. Many mines and quarries will report blast times but are often reluctant to release detailed information on explosion sizes because this may become the basis for damage claims. More forthcoming were suppliers of chemical explosive, and from them we soon learned of 14 mines in the western and mid-western United States that routinely use ANFO for ripple-fired explosions in the range of 100 to 500 tons. Table 1 lists the number of large blasts per year and their sizes at these 14 mines.

There are many more mining explosions above 40 tons, and blasting above 10 tons occurs "all the time" in the west and mid-west. At times of lessened economic interest in mining these numbers of explosions are somewhat reduced, but individual mines are geared up to work with explosions of a certain size so the sizes do not change greatly. Because the shots are rippled-fired, the observed seismic signals are more complex and are significantly reduced in amplitude below what would be observed if the total charge were set off at the same instant in one location. Scientific papers on the resulting seismic signals have been published by Greenhalgh et al. (1980) and Greenhalgh (1980), who report on blasts consisting of tens of rows each with 10 or more holes, each hole filled with less than 1 ton of ANFO. A typical pattern in their studies was 20 rows, and evidence of delays of about 0.2 sec between rows was apparent in the observed seismic waveforms. (The ripple-firing method minimizes ground vibration and fractures rock more efficiently.) Smith (1989) describes high-frequency 
TABLE 1

Numbers and Stzes of Large Chemical

EXPLOSIONS IN 14 U.S. WESTERN

AND Mid-Westenn Mines

\begin{tabular}{ll}
$\begin{array}{c}\text { No. of Large Blasts } \\
\text { per Year }\end{array}$ & \multicolumn{1}{c}{$\begin{array}{c}\text { Size of Large Blasts } \\
\text { (Tons of ANFO) }\end{array}$} \\
\hline 50 & $50-100$ \\
40 & $40-80$ \\
50 & 100 (one at 600) \\
20 & 200 \\
80 & 100 \\
25 and 150 & 100 and 60, respectively \\
100 & 100 \\
50 & 400 \\
25 & 500 \\
20 & 350 \\
30 & 200 \\
50 & 150 and above \\
15 & 200 \\
15 & 200 \\
\hline
\end{tabular}

seismic signals a few hundred $\mathrm{km}$. from explosions at a taconite mine. He and Hedlin et al. (1989) describe the effects of ripple firing on the spectra of observed seismograms.

Another source of information on how many explosions occur in a limited part of the United States was a preliminary study done at the Lamont-Doherty Geological Observatory of the number of blasts detected on the New York State Seismic Network in a single month. It was found that for April 1986 about 19 explosions were detected per weekday.

The present study of blasting activity in the United States is based on three different sources of information: the U. S. Bureau of Mines (USBM); the Mine Safety and Health Administration (MSHA); and Vibra-Tech Engineers, Inc.

The USBM collects data on "apparent consumption" of explosives, i.e., on amounts manufactured. The information is derived from explosives manufacturers and is compiled for a given year by state for different types of explosive.

The MSHA maintains a list of active and inactive surface and underground mines. Although there is no indication of blasting activity we can infer such activity for certain types of operations, and we will compare location counts with this list.

Vibra-Tech Engineers, Inc., are consultants to the mining, quarrying, construction, and explosive-using industries. A major concern of these industries is their environmental impact, such as the effect of ground vibration and air overpressure, due to explosions, on nearby structures. Many mine operators use Vibra-Tech, or other consultants, to monitor the levels of vibration and overpressure in order to document compliance with local regulations limiting the levels of vibration and overpressure. From Vibra-Tech records for 1987, we have acquired data on explosion location, date, approximate time of day, total explosives used in each shot, and maximum pounds per delay period. This database is a detailed description of 20,813 blasts carried out at 532 locations.

Note that, for regulatory purposes, the "maximum pounds per delay period" is defined to be the amount of explosives designed to be detonated within an 8 
msec interval; the weights of two explosive charges will be counted together if their nominal firing times are within $8 \mathrm{msec}$.

In sections that follow, we describe in more detail the data from our three different sources (USBM, MSHA, Vibra-Tech). We then describe our methods for extrapolating the Vibra-Tech data to obtain an overview of blasting for the whole United States and conclude with some comments on the relevance of these statistics to the nuclear explosion discrimination problem.

\section{Data on Blasting from the U.S. Bureau of Mines}

An annual USBM publication (see references) reports the total apparent consumption of industrial explosives each year for each state for different types of operation (mining, quarrying), using information supplied by manufacturers of explosives.

Table 2 reproduces the summary figures for five different classes of explosive for the years 1986 to 1989 . In Table 2, permissibles are high explosives like dynamites) that may be used in underground mines. ANFO is the predominant explosive in use today. It attracted wide attention for the first time in April 1947 when two Liberty ships carrying ammonium nitrate, a fertilizer, blew up in Galveston County, Texas, with the loss of about 600 lives (Kinney and Graham, 1985). Water gels, slurries, and emulsions are ANFO-like products that have been modified to make them usable in the presence of water. Note from Table 2 that the bulk of the apparent U.S. consumption is unprocessed ammonium nitrate (AN), which is mixed with fuel oil (often on-site at mines) by other manufacturers.

We shall be concentrating on the statistics for 1987, showing a total of about two megatons, which is representative of recent years.

The USBM reports for 1987 that, of the two megaton total, $72 \%$ was used in the mining of coal, $7.5 \%$ in mining for metal ores, $11 \%$ in quarrying and nonmetal mining, and $7 \%$ for construction. Surface mining for coal uses large explosions, where possible, since the purpose is to remove overburden. Most of the coal is used in generation of electricity, an industrial activity that is not greatly affected by short-term (1- or 2-year) business cycles. Seven states collectively manufactured $55 \%$ of the explosive, with Kentucky making more than twice as much as the next state, Pennsylvania, followed in order by Ohio, West Virginia, Wyoming, Georgia, and Alabama. Table 3 shows in order the 15 states making more than 50,000 tons of explosives in 1987, with breakdown into different types of blasting agent (high explosives are not shown, the totals are relatively small). Also shown is the breakdown into usage in coal mining and

TABLE 2

AMOUNTS OF INDUSTRIAL EXPLOSIVEs Sold FOR USE IN THE U.S., 1986-1989 (IN METRIC TONS)

\begin{tabular}{lrrrr} 
& \multicolumn{1}{c}{ Class of Explosive } & \multicolumn{1}{c}{1986} & \multicolumn{1}{c}{1988} & \multicolumn{1}{c}{1989} \\
\hline Permissibles & 16,100 & 15,400 & 12,600 & 10,400 \\
Other high explosives & 59,900 & 65,100 & 68,500 & 64,000 \\
Water gels, slurries, emulsions & 191,000 & 218,800 & 299,200 & 291,800 \\
ANFO & 294,700 & 286,300 & 394,300 & 348,600 \\
Unprocessed AN & $1,221,400$ & $1,459,000$ & $1,378,500$ & $1,469,400$ \\
Totals & $1,783,100$ & $2,044,700$ & $2,153,000$ & $2,184,200$ \\
\hline
\end{tabular}


TABLE 3

Tons of Industrial Blasting Agents Sold for Consumption in the U.S. iN 1987, and the Usage in Coal and Metal Mining, for the 15 States Manufacturing

MORE THan 50,000 TONS OF Explosives (USBM Data)

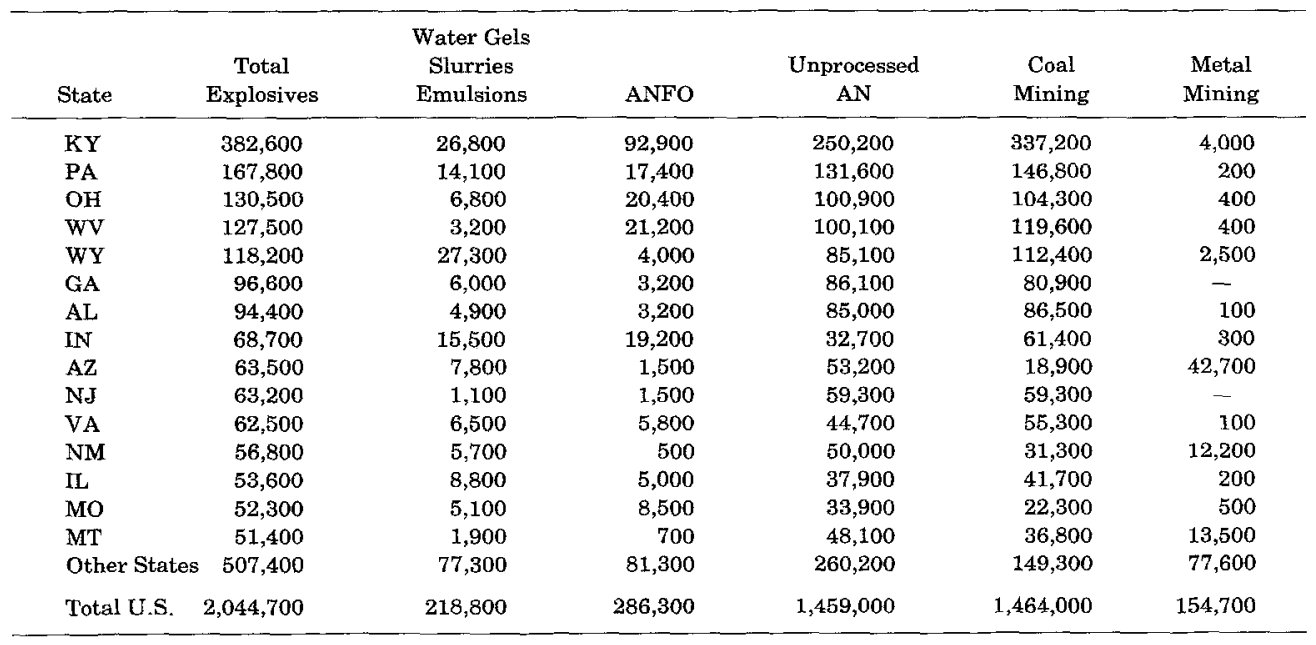

metal mining. Note that the USBM figures, by state, are for explosives produced; consumption presumably may be in a different state.

\section{Data Obtained from the Mine Safety and Health Administration}

The MSHA maintains lists of active, temporarily abandoned, and permanently abandoned mines, both surface and underground, in the United States. Table 4 and Figures 1 to 4 summarize the MSHA information most pertinent to our survey. Table 4 shows the distribution, by state and by type, of about 4000 active surface mines. In Figures 1 to 3 we show the distribution by state of coal mines, metal mines, and quarries for crushed and broken stone. Figure 4 shows total surface mines by state.

\section{Data on Blasting Obtained from Vibra-Tech}

As noted above, the records obtained by Vibra-Tech are related to potential claims of damage from blasting to residential and other structures. Quarries must be fairly close to their market (generally within a 30 -mile radius) to be competitive; therefore, they often have neighbors and monitor routinely. In contrast, metal, coal, and specialty mineral mines, which typically shoot the largest shots, are located where the ore or coal is and may be at a substantial distance from neighbors. Therefore, they sometimes do not monitor their shots. Coal mines generally tend to shoot smaller shots where they are close to residential areas, and then they routinely monitor. Construction operations are very often in congested areas, shoot very small shots, and monitor. There are exceptions to the above, but, in general, we would expect to find that Vibra-Tech records are skewed to smaller shots, both in terms of total shot size, and pounds per delay, relative to all mine blasting. Except for a very few of the locations, our data as reported in this study are from mines and quarries.

For 1987, Vibra-Tech had monitoring records from 17 different offices-four in Pennsylvania and one in each of the following states: Alabama, Colorado, 


\section{COUNT RANGES}

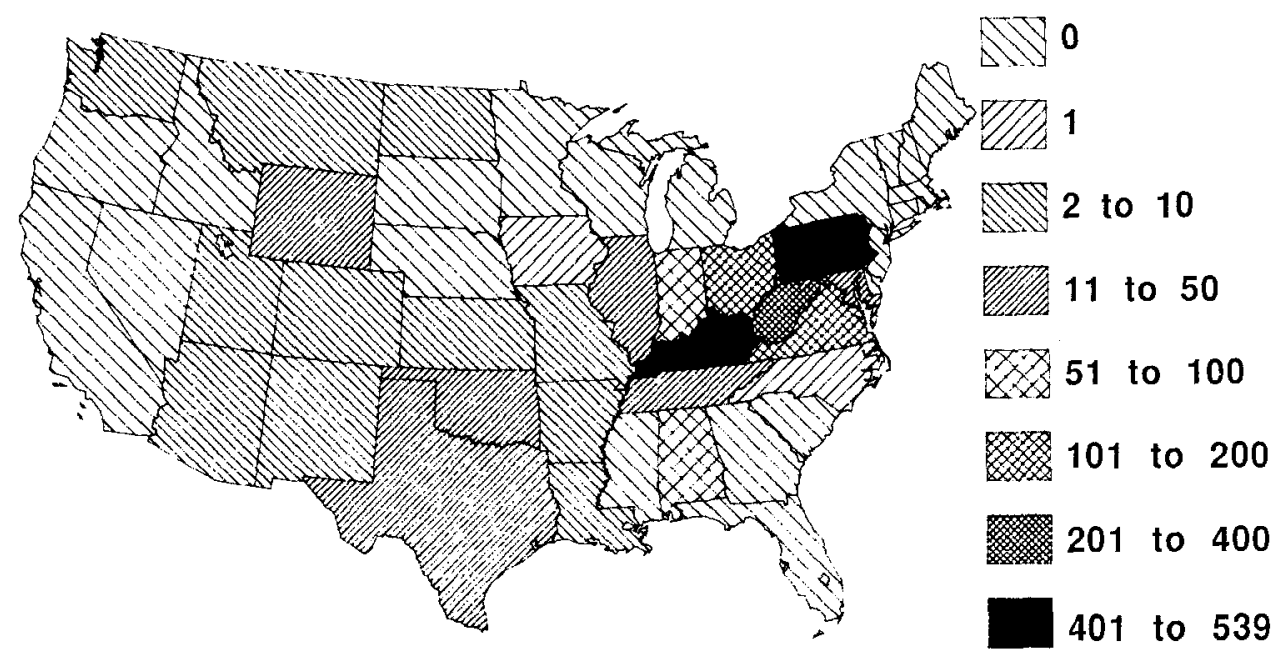

Fig. 1. These surface coal mine locations from MSHA have many shots of large size and constitute both the bulk of explosive use (according to USBM data) and dominate the Vibra-Tech data for large shots. Note that Wyoming does not have many mines. However, it uses large amounts of explosives, so some mines must have many large shots. The largest shot in our study, just under $3,000,000 \mathrm{lb}$ (1350 metric tons) was from Wyoming.

\section{COUNT RANGES}

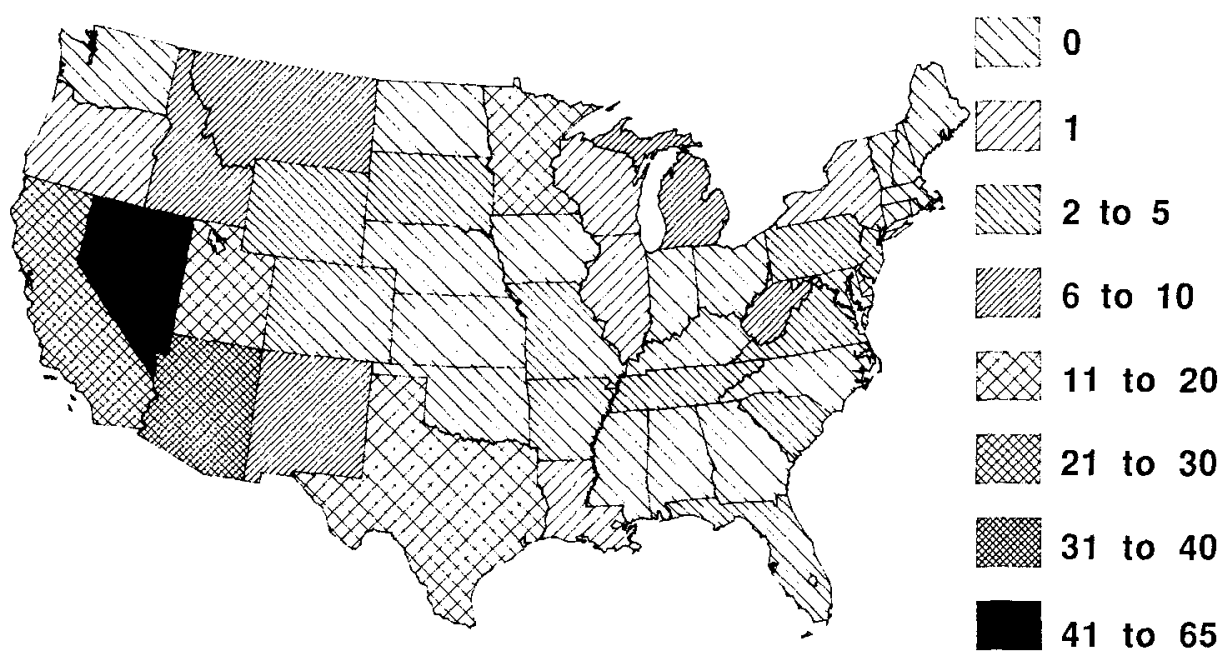

FIG. 2. Surface metal mine locations from MSHA. This is the worst-represented type of blasting in the Vibra-Tech database, since these mines tend to be remote and do not monitor. Vibra-Tech does have records from gold mines in California, whose shots are of average size, in the range of 10 tons total; and also from iron mines in Michigan (upper peninsular), where the shots are large (some greater than 50 tons total). Metal mines shoot large shots: the largest mining shot on record (as reported by the Institute of Makers of Explosives) is a 4.1 million lb shot at a copper mine in Arizona in 1983. 


\section{COUNT RANGES}

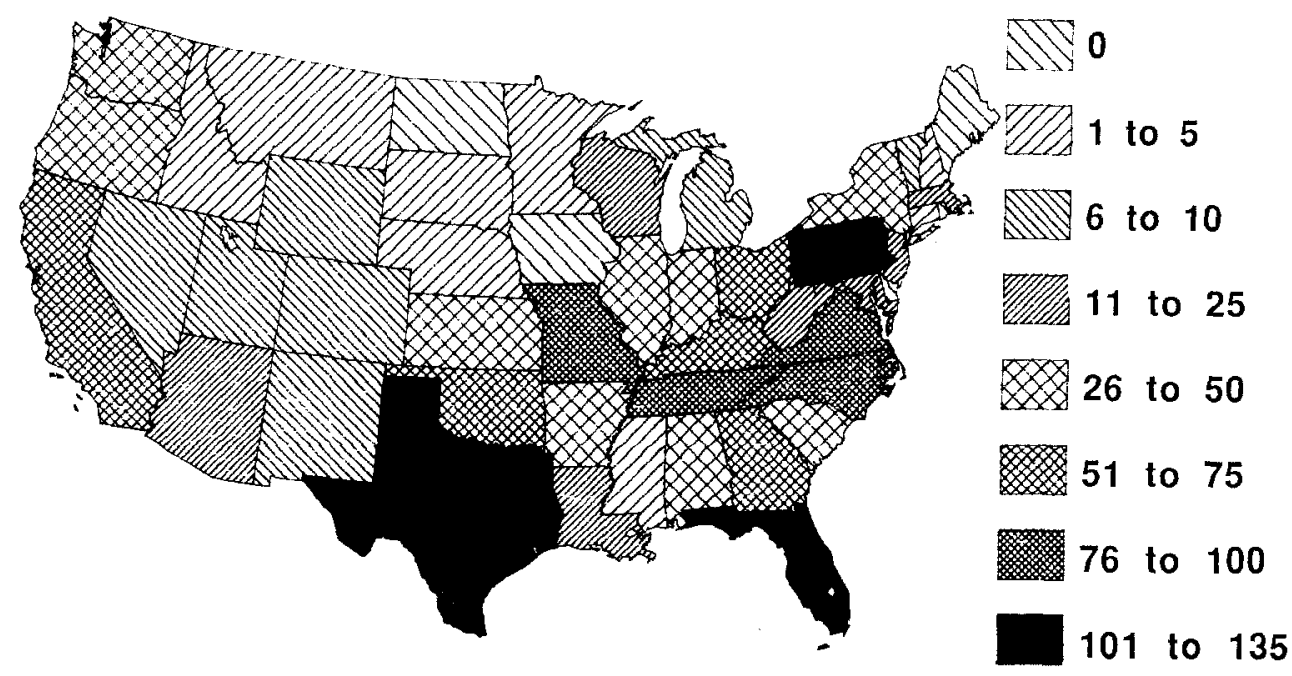

Frg. 3. Locations from MSHA of quarries for crushed and broken stone. Such quarries are replaced in much of the West by sand and gravel operations, which do not blast. Note the many quarries in Texas, Florida, North Carolina, and Missouri. These states do not have very high total explosives use, but they blast at many locations.

\section{COUNT RANGES}

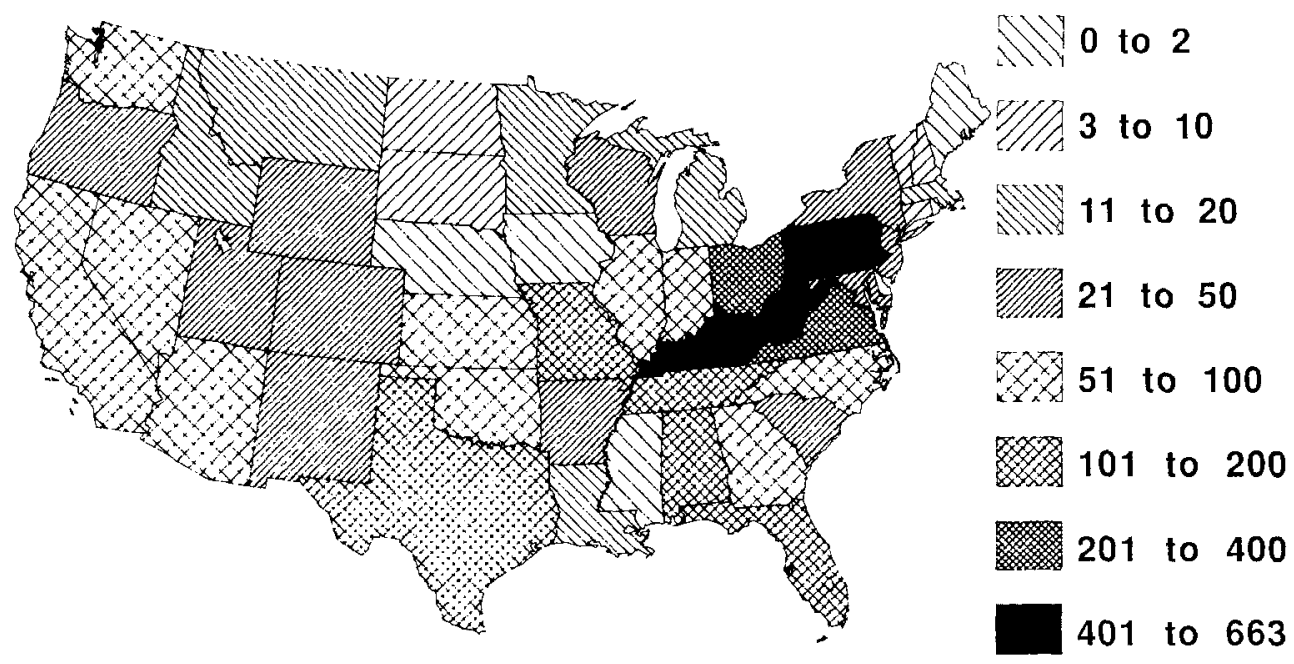

FIG. 4. This is a total of coal, metal, crushed and broken stone, lime, and cement surface operations listed by MSHA. There may be blasting in some other mining operations (such as for specialty minerals). There is also blasting for underground mining and construction, but we have specifically excluded these because they tend to be small shots. The distribution of mines is, in general, consistent with the use of explosives (see Table 3). Variations are principally due to the fact that quarries tend to be smaller in size and constitute a substantial fraction of the mine count (see Fig. 3). 
TABLE 4

MSHA Summary of Active Surface Mines

\begin{tabular}{|c|c|c|c|c|c|c|}
\hline State & Coal & Metal & Crushed Stone & Cement & Lime & Total \\
\hline $\mathrm{AL}$ & 71 & 0 & 36 & 5 & 5 & 117 \\
\hline $\mathrm{AK}$ & 5 & 4 & 38 & 0 & 0 & 47 \\
\hline $\mathrm{AZ}$ & 3 & 31 & 15 & 1 & 2 & 52 \\
\hline $\mathrm{CA}$ & 0 & 23 & 68 & 5 & 4 & 100 \\
\hline $\mathrm{CO}$ & 9 & 2 & 7 & 2 & 1 & 21 \\
\hline CT & 0 & 0 & 3 & 0 & 0 & 3 \\
\hline $\mathrm{DE}$ & 0 & 1 & 0 & 0 & 0 & 1 \\
\hline FL & 0 & 2 & 115 & 6 & 1 & 124 \\
\hline GA & 0 & 0 & 68 & 2 & 0 & 70 \\
\hline IA & 1 & 0 & 0 & 0 & 0 & 1 \\
\hline ID & 0 & 6 & 3 & 1 & 1 & 11 \\
\hline IL & 33 & 1 & 46 & 1 & 1 & 82 \\
\hline IN & 56 & 0 & 41 & 1 & 1 & 99 \\
\hline KS & 3 & 0 & 48 & 0 & 0 & 51 \\
\hline KY & 498 & 0 & 57 & 1 & 0 & 556 \\
\hline LA & 2 & 1 & 11 & 0 & 1 & 15 \\
\hline MA & 0 & 0 & 11 & 0 & 0 & 11 \\
\hline MD & 27 & 0 & 20 & 1 & 2 & 50 \\
\hline ME & 0 & 0 & 0 & 1 & 0 & 1 \\
\hline MI & 0 & 6 & 9 & 1 & 2 & 18 \\
\hline MN & 0 & 13 & 5 & 0 & 0 & 18 \\
\hline MO & 7 & 2 & 91 & 0 & 1 & 101 \\
\hline MS & 0 & 0 & 2 & 0 & 0 & 2 \\
\hline MT & 7 & 9 & 4 & 0 & 0 & 20 \\
\hline $\mathrm{NC}$ & 1 & 0 & 85 & 0 & 1 & 87 \\
\hline ND & 8 & 0 & 0 & 0 & 0 & 8 \\
\hline NE & 0 & 0 & 2 & 0 & 0 & 2 \\
\hline NH & 0 & 0 & 4 & 0 & 0 & 4 \\
\hline $\mathrm{NJ}$ & 0 & 2 & 20 & 0 & 0 & 22 \\
\hline NM & 6 & 8 & 8 & 0 & 0 & 22 \\
\hline NV & 0 & 65 & 7 & 2 & 2 & 76 \\
\hline NY & 0 & 1 & 37 & 3 & 0 & 41 \\
\hline $\mathrm{OH}$ & 159 & 0 & 68 & 0 & 2 & 229 \\
\hline OK & 17 & 0 & 52 & 0 & 0 & 69 \\
\hline OR & 0 & 1 & 37 & 2 & 0 & 40 \\
\hline PA & 539 & 2 & 107 & 6 & 9 & 663 \\
\hline RI & 0 & 0 & 0 & 0 & 0 & 0 \\
\hline SC & 0 & 3 & 34 & 0 & 2 & 39 \\
\hline SD & 0 & 5 & 3 & 1 & 1 & 10 \\
\hline TN & 42 & 3 & 81 & 1 & 1 & 128 \\
\hline $\mathrm{TX}$ & 12 & 14 & 135 & 3 & 2 & 166 \\
\hline UT & 2 & 12 & 6 & 1 & 0 & 21 \\
\hline VA & 153 & 2 & 86 & 1 & 1 & 243 \\
\hline VT & 0 & 0 & 10 & 0 & 0 & 10 \\
\hline WA & 2 & 0 & 46 & 4 & 0 & 52 \\
\hline WI & 0 & 1 & 21 & 0 & 4 & 26 \\
\hline WV & 396 & 6 & 20 & 0 & 1 & 423 \\
\hline WY & 25 & 4 & 6 & 0 & 0 & 35 \\
\hline Total & 2084 & 230 & 1573 & 52 & 48 & 3987 \\
\hline
\end{tabular}


Georgia, Florida, Illinois, Kentucky, Maryland, Missouri, New Jersey, New York, North Carolina, Texas, and West Virginia.

From these 17 offices engaged in monitoring, information was gathered on shot location (to the nearest tenth of a degree), date and approximate local time, total explosives used, and maximum pounds per $8 \mathrm{msec}$ interval. Detailed Vibra-Tech records for 1987 comprise 294,355,502 total pounds of explosive, detonated in 20,813 shots at 532 locations. This information is summarized first in Table 5 and Figures 5 to 10, where each shot is characterized only in terms of total charge. We describe the distribution of delays later.

The shot distribution, shown spatially in Figure 5, is skewed to the regions where Vibra-Tech has offices. The distribution of explosive use, shown in Figure 6 , is similarly skewed but does compare favorably with with USBM data (Table

TABLE 5

Total Explosive Use by State Monitored by Viera-Tech IN 1987

\begin{tabular}{|c|c|c|c|c|}
\hline State & No. of Locations & No. of Shots & Pounds of Explosive & $\%$ Monitored \\
\hline $\mathrm{AL}$ & 7 & 1,053 & $71,756,225$ & 35 \\
\hline $\mathrm{AZ}$ & 2 & 5 & 273,574 & 0 \\
\hline $\mathrm{CA}$ & 2 & 5 & 68,250 & \\
\hline $\mathrm{CO}$ & 6 & 59 & 262,975 & \\
\hline $\mathrm{CT}$ & 4 & 66 & 399,735 & \\
\hline FL & 4 & 268 & 356,904 & \\
\hline GA & 33 & 1,806 & $26,843,500$ & 13 \\
\hline IA & 15 & 82 & 684,137 & \\
\hline IL & 12 & 491 & $1,444,567$ & \\
\hline IN & 10 & 739 & $4,218,888$ & 3 \\
\hline KS & 1 & 41 & 110,190 & \\
\hline KY & 28 & 2,146 & $49,739,705$ & 6 \\
\hline MA & 2 & 12 & 121,849 & \\
\hline MD & 23 & 1,156 & $12,583,118$ & \\
\hline MI & 1 & 132 & $17,285,712$ & \\
\hline MN & 3 & 464 & $2,283,217$ & \\
\hline MO & 10 & 147 & $1,125,835$ & \\
\hline MT & 1 & 15 & 62,638 & \\
\hline $\mathrm{NC}$ & 31 & 1,199 & $5,567,877$ & \\
\hline $\mathrm{NH}$ & 1 & 12 & 2,698 & \\
\hline NJ & 12 & 641 & $5,545,928$ & 4 \\
\hline NY & 36 & 879 & $7,997,119$ & \\
\hline $\mathrm{OH}$ & 4 & 101 & 496,906 & 0 \\
\hline PA & 202 & 6,736 & $61,649,765$ & 17 \\
\hline $\mathrm{SC}$ & 11 & 537 & $4,994,448$ & \\
\hline $\mathrm{TN}$ & 8 & 406 & $1,989,543$ & \\
\hline $\mathrm{TX}$ & 7 & 197 & 755,350 & \\
\hline VA & 48 & 1,434 & $9,528,789$ & \\
\hline WI & 1 & 5 & 14,249 & \\
\hline WV & 2 & 42 & $1,034,134$ & 0 \\
\hline WY & 5 & 81 & $5,157,677$ & 2 \\
\hline Total & 534 & 20,974 & $294,355,502$ & \\
\hline
\end{tabular}

The appropriate figure for the number of records with known total explosive is 20,813 rather than 20,974 , since no total pounds were listed for a few of the recorded shots; the lower number is used in the text. The last column gives the Vibra-Tech monitored explosive as a percentage of total explosive sold (see Table 3), for the top 10 explosive-manufacturing states. 


\section{COUNT RANGES}

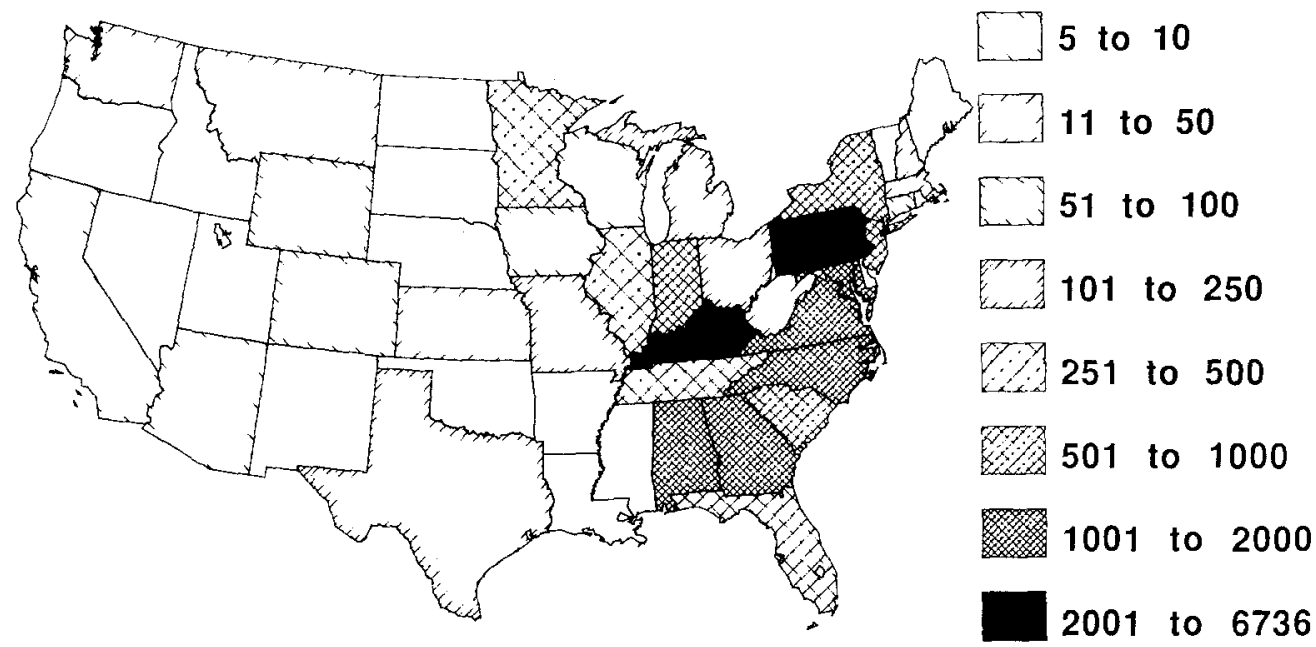

FIG. 5. Map of total shots recorded by Vibra-Tech in 1987.

\section{POUNDS (1000's)}

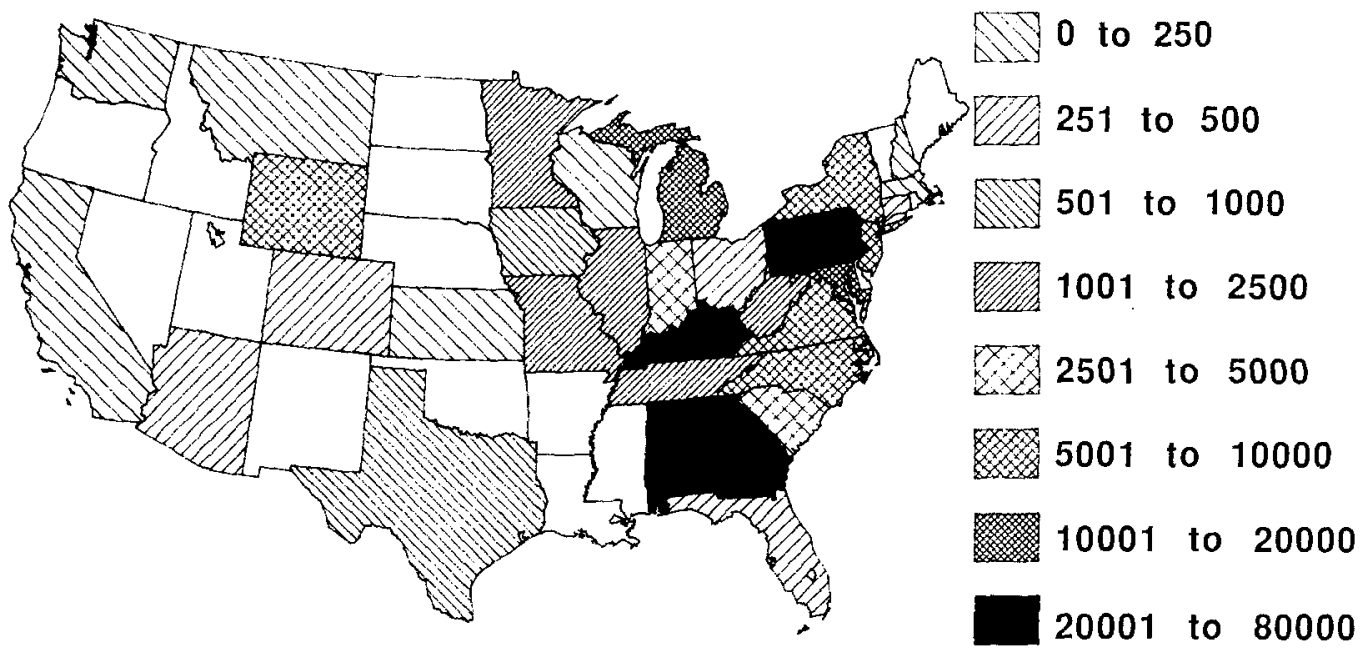

FIG. 6. Map of total explosive use, monitored by Vibra-Tech in 1987.

3) in showing highest levels for Pennsylvania, Kentucky, Alabama, and Georgia.

In order to summarize the distribution of sizes of the 20,813 monitored shots, we broke the data into three categories: small, medium, and large shots, where small is less than $10,000 \mathrm{lb}$ total; medium is from 10,000 to $100,000 \mathrm{lb}$; and large is above $100,000 \mathrm{lb}$. Figure 7 shows the number of medium shots monitored by Vibra-Tech, by state, for 1987. Shots of this size are used in coal and metal mining and in quarries, and the similarity between Figure 7 and the map of all MSHA surface mine locations (Fig. 4) is an indication that Vibra-Tech 
monitoring data is representative of U.S. blasting for shots in the range from 5 to 50 tons.

Figure 8 shows, by state, the number of large shots, monitored in 1987. Note that distribution is concentrated in the coal mining states. Arizona, while primarily known for copper mines, also has two very large coal mines. The high concentration of large blasts in Michigan is from upper peninsular taconite mines (iron ore).

To show the distribution of shot sizes in more detail (i.e., better than the

\section{COUNT RANGES}

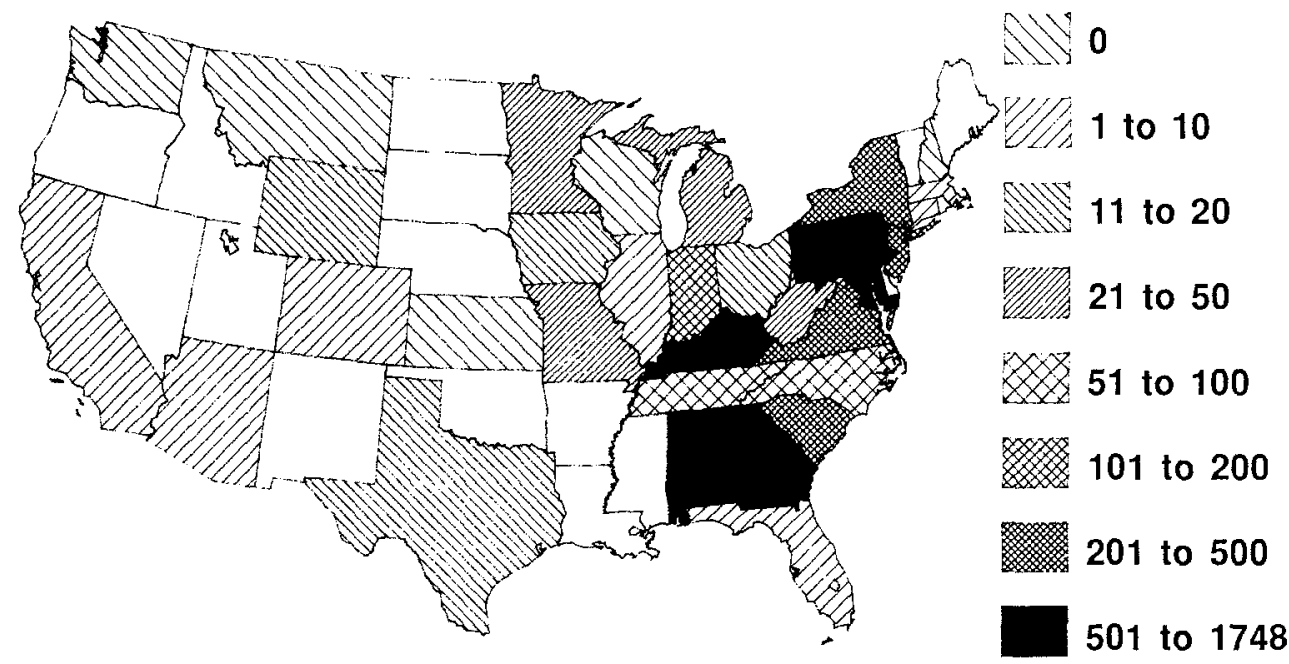

FIG. 7. Map showing distribution of Vibra-Tech monitored shots in size range from 10,000 to $100,000 \mathrm{lb}$ (approximately 5 to 50 tons) in 1987.

\section{COUNT RANGES}

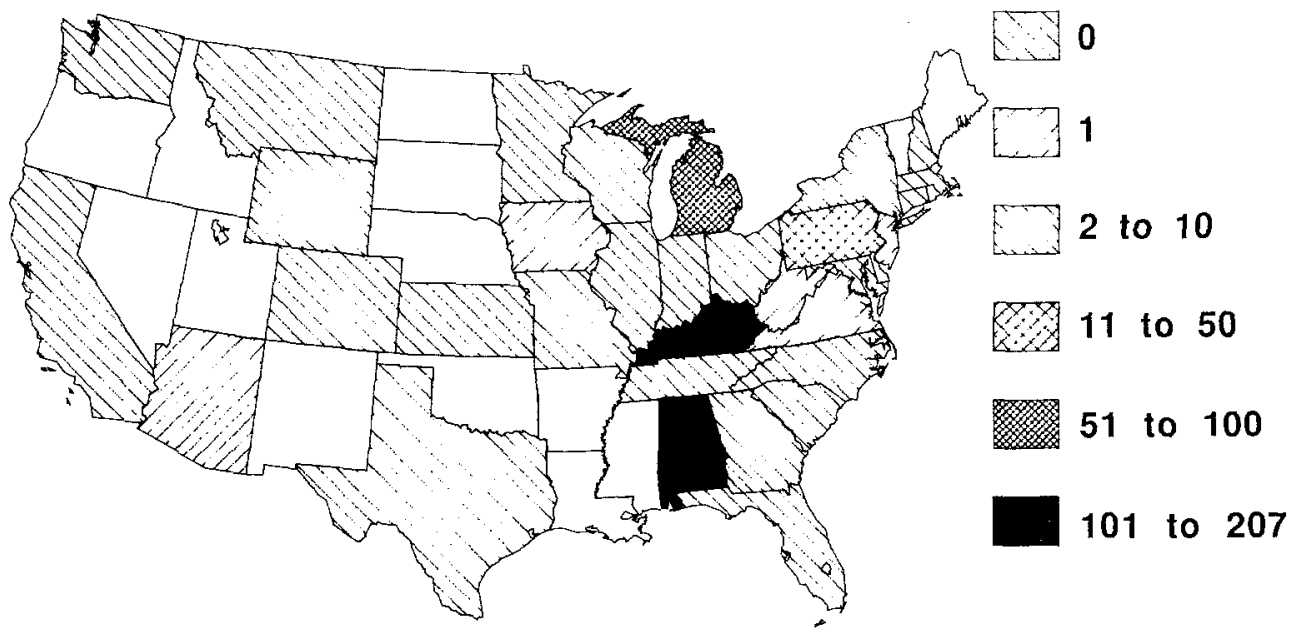

FIG. 8. As Figure 7, but for Vibra-Tech monitored shots greater than 100,000 lb. 


\section{Total Pounds Per Shot}

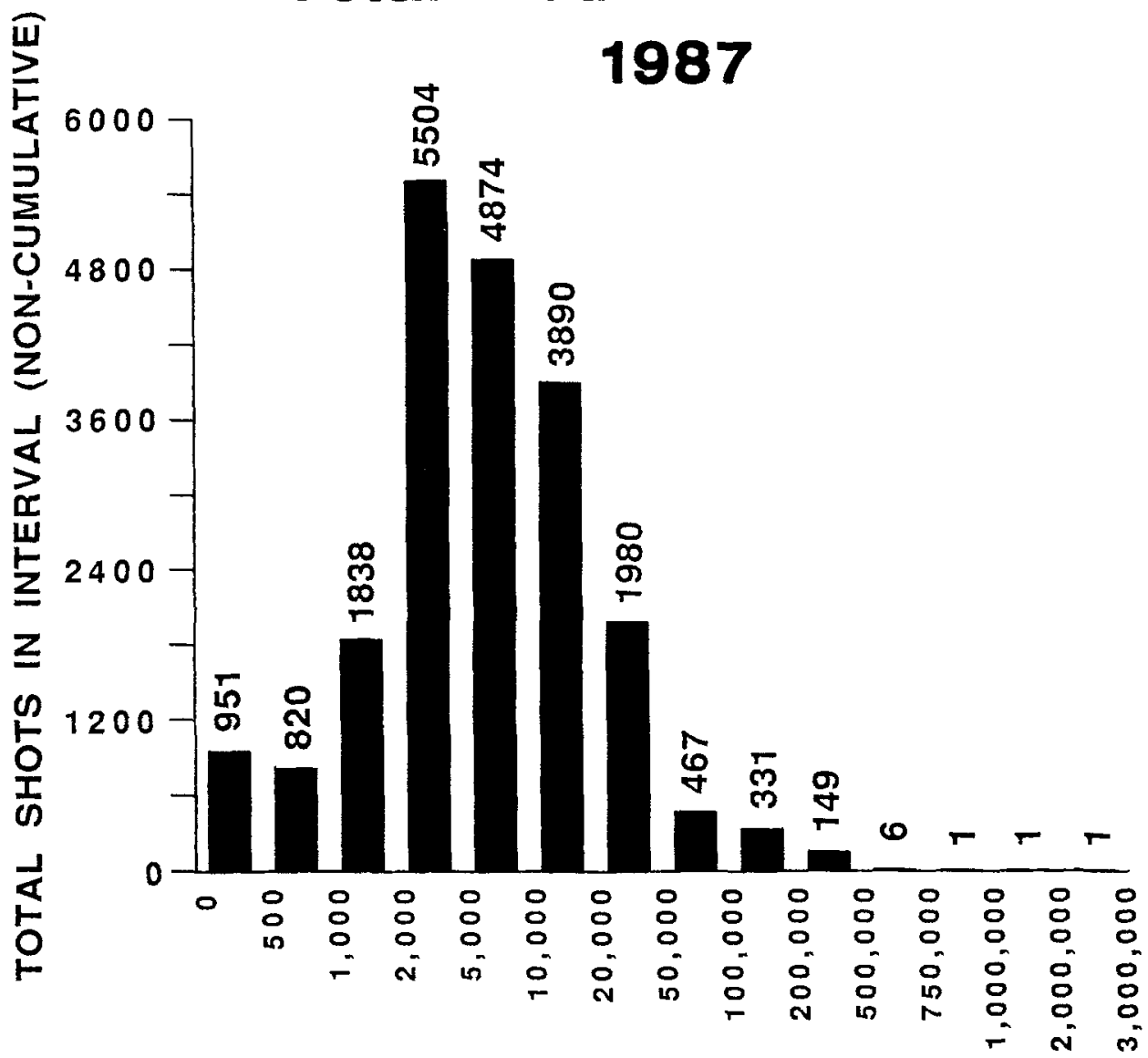

Fic. 9. Histogram of Vibra-Tech monitored shots in various ranges; total lb.

three categories of small, medium, and large), we show in Figure 9 a histogram for the 20,813 monitored shots. Almost three-quarters of the shots fall in the range of 2,000 to $20,000 \mathrm{lb}$ total explosive.

Note that there is a slight peak at the lowest range ( 0 to $500 \mathrm{lb}$ ). If more construction shots were included in the data, this peak would be further emphasized. There are almost 500 shots greater than $100,000 \mathrm{lb}$. The largest shot monitored by Vibra-Tech in 1987 was 2,968,998 lb (1350 tons) in a Wyoming coal mine on March 20.

Another way to describe the distribution of shot sizes is in terms more closely related to the usual method for describing the size distribution of earthquakes, in which the cumulative count $N=N(m)$ is defined to be the number of earthquakes occurring (in some time interval) with magnitude greater than $m$. Working with the logarithm of shot size, we show in Figure 10 the cumulative count of Vibra-Tech monitored shots in 1987.

It is interesting that Figure 10 indicates a slope of about -1 from 1 to 100 tons. This is remarkably similar to the result

$$
N \propto 10^{-b m_{b}}
$$




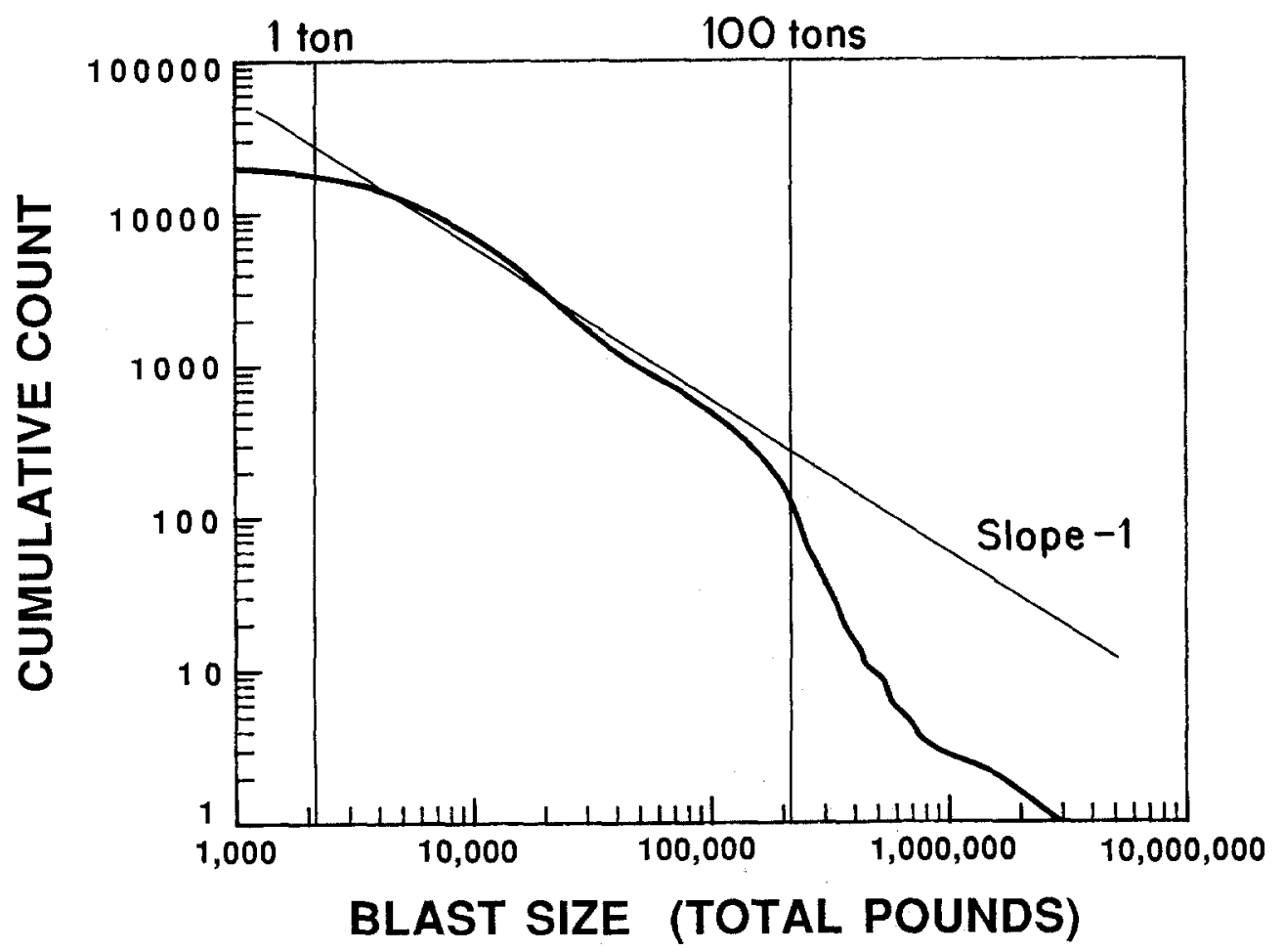

FIG. 10. Cumulative count versus blast size for Vibra-Tech monitored shots.

with $b$-value near unity, as found for the distribution of body-wave magnitudes for earthquakes. The fact that the $b$-value in Figure 10 is greater than unity for shots above 100 tons is perhaps in part because Vibra-Tech undersamples this size range.

Finally, in this section on monitored explosions, we comment briefly on the distribution of delays. We have information on pounds per delay for 20,759 shots, and a histogram is shown in Figure 11. The distribution is unimodal, with a sharp peak in the 200- to 500-lb range. This peak is a consequence of physical limitations on borehole diameter and depth. Apart from a couple of shots with delays in the range from 30 to 100 tons, the remaining shots (including 487 shots with total charge greater than 50 tons) have delays less than 10 tons each. We found that most shots had the $1 \mathrm{~b}$ per delay approximately 2 to $5 \%$ of the total explosive in the shot. The only shots which used no delay were all small: ripple-firing was the universal practice for medium and large shots. Further information on the distribution of delays is given in Richards et al. (1991).

\section{Comparison of Monitored Shots, with USBM ANd MSHA Data}

Since we are interested in estimating the number of large blasts annually in the United States, we have sought to extrapolate the Vibra-Tech data on monitored shots using information from USBM and MSHA as constraints. In this section, we first state our initial expectations-our guesses--before we had any data. We then show how these initial estimates can be refined.

We initially estimated that Vibra-Tech has about $40 \%$ of the market share for 


\section{Pounds Per Delay Per Shot}

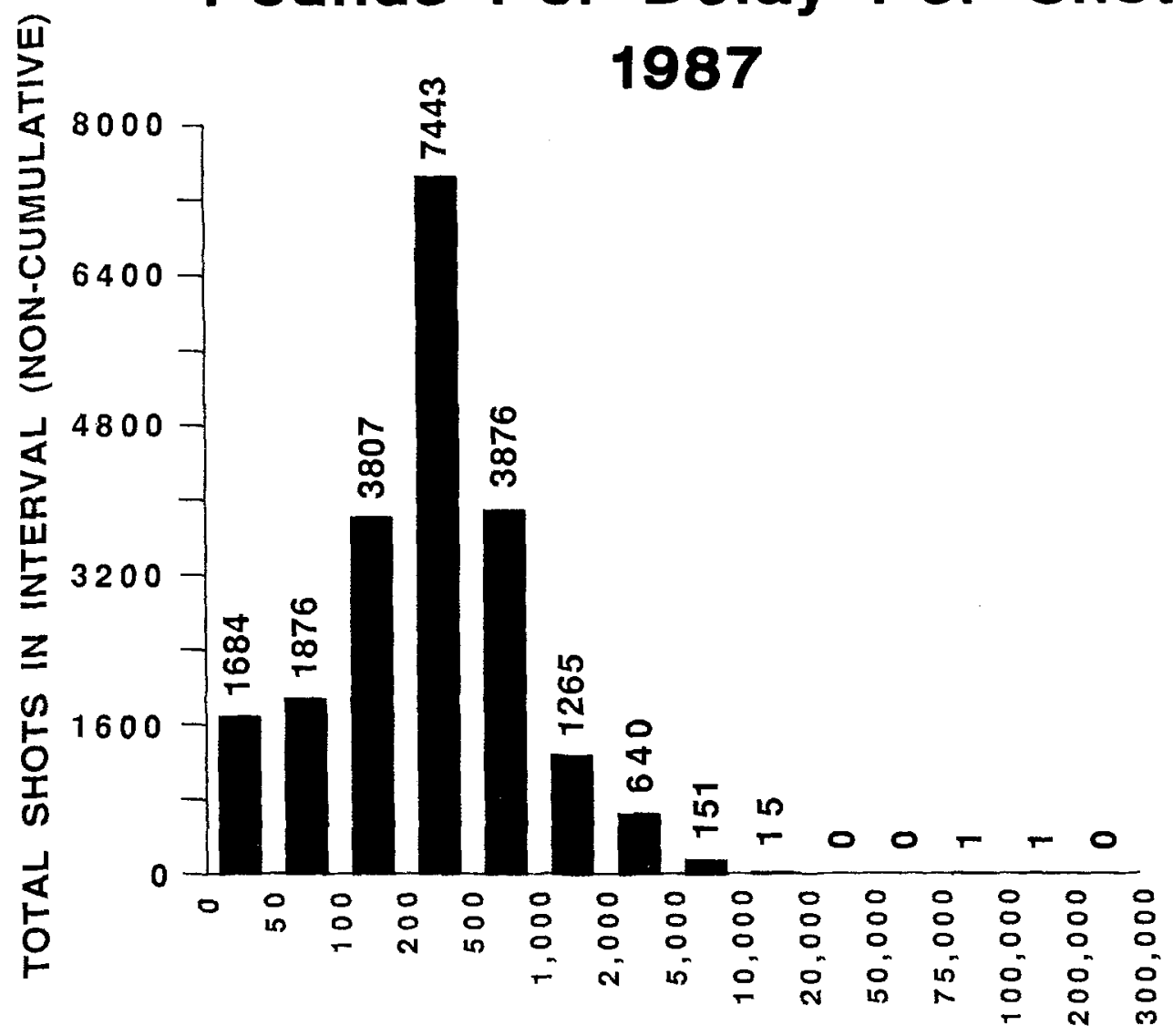

FIG. 11. Histogram of $\mathrm{lb}$ per delay for monitored shots.

blast monitoring and that approximately half of the surface mining operations use a vibration consultant. On this basis, Vibra-Tech would have records for about $20 \%$ of the operations in the United States. However, this is the percentage of locations, rather than explosive use. Since records of explosive use will be skewed towards smaller shots, our initial expectation was that an even smaller percentage of the total explosive use would be covered, perhaps about $10 \%$. Operations that shoot large shots will generally shoot fewer shots, and we expected that our monitoring data would cover about $15 \%$ of the shots-that is, between the percentages for locations (20\%) and for total explosive use $(10 \%)$.

We can refine these initial estimates, and reach conclusions on the numbers of large shots, by taking the following three steps.

Step 1. It appears that Vibra-Tech has records in 1987 for fewer than $20 \%$ of the blasting operations in the United States, since the MSHA lists 3987 active surface mines (see Table 4) and Vibra-Tech monitored 532 locations. This is $13 \%$ of the MSHA total. Similarly, Vibra-Tech monitored somewhat less than $10 \%$ of the total explosive used since about 2 megatons are reported by USBM (Table 3) and Vibra-Tech monitored about 134 kilotons (kt) (294 million lb; see Table 5). This is $6.5 \%$ of the USBM total. 
TABLE 6

Summary by Shot Size of Vibra-Tech Monttored Explosions, and Estimated Annual U.S. Total Counts

\begin{tabular}{lccc}
\hline \multicolumn{1}{c}{ Shot Size } & $\begin{array}{c}\text { Vibra-Tech } \\
\text { Count }\end{array}$ & $\begin{array}{c}\text { Estimated } \\
\text { \% of total }\end{array}$ & $\begin{array}{c}\text { Estimated } \\
\text { Total Count }\end{array}$ \\
\hline Small $(<10,000 \mathrm{lb})$ & 13,987 & $?$ & \\
Medium & 6,337 & 10 & 65,000 \\
Large $(>100,000 \mathrm{lb})$ & 489 & 5 & 10,000 \\
\hline
\end{tabular}

The estimates in the last column are somewhat conservative, i.e., best estimates would be somewhat lower.

Step 2. The percentage for the number of shots monitored by Vibra-Tech, initially estimated as $15 \%$, must also be scaled back somewhat. We would still expect this percentage to lie between the percentages for locations $(13 \%)$ and total explosive use $(6.5 \%)$, hence we estimate that Vibra-Tech monitored about $10 \%$ of the shots.

Step 3. We recognize that large shots ( $>100,000 \mathrm{lb}$, i.e., about 50 tons) are under-represented in the Vibra-Tech database, perhaps by a factor of 2 . (We show this is a conservative estimate, in discussion of Table 6, below.)

From these three steps and their associated assumptions, we therefore estimate that Vibra-Tech monitored about 5\% of the large U.S. shots in 1987. Our conclusions are summarized in Table 6.

Another way to improve our initial estimates is to explore the consequences of the rule

$$
N \propto 10^{-b \log W}
$$

for the cumulative count (see Fig. 10). This rule is equivalent to a power law,

$$
N=a W^{-b}
$$

and we can relate it to the total amount of explosive whose use was monitored by Vibra-Tech.

The total (294 million $\mathrm{lb}$, from Table 5) is about $135 \mathrm{kt}$, and it is interesting to determine whether this amount is principally built up from the fewer large explosions ( $>100$ tons), or from the medium range for which we have reason to believe the Vibra-Tech database is representative of U.S. blasting, or from the large number of small explosions ( $<1$ ton). The problem is similar to that of identifying the principal contribution to the total moment for a set of earthquakes associated with a power law distribution of fault sizes (Scholz and Cowie, 1990).

The total amount of explosive accumulated for all shots between sizes $W_{\min }$ and $W_{\max }$ is related to $N$ via an integral:

$$
\text { total explosive }=-\int_{W_{\min }}^{W_{\max }} W \frac{d N}{d W} d W
$$

For the cumulative count shown in Figure 12, we can let $W_{\min } \rightarrow 0$ and 


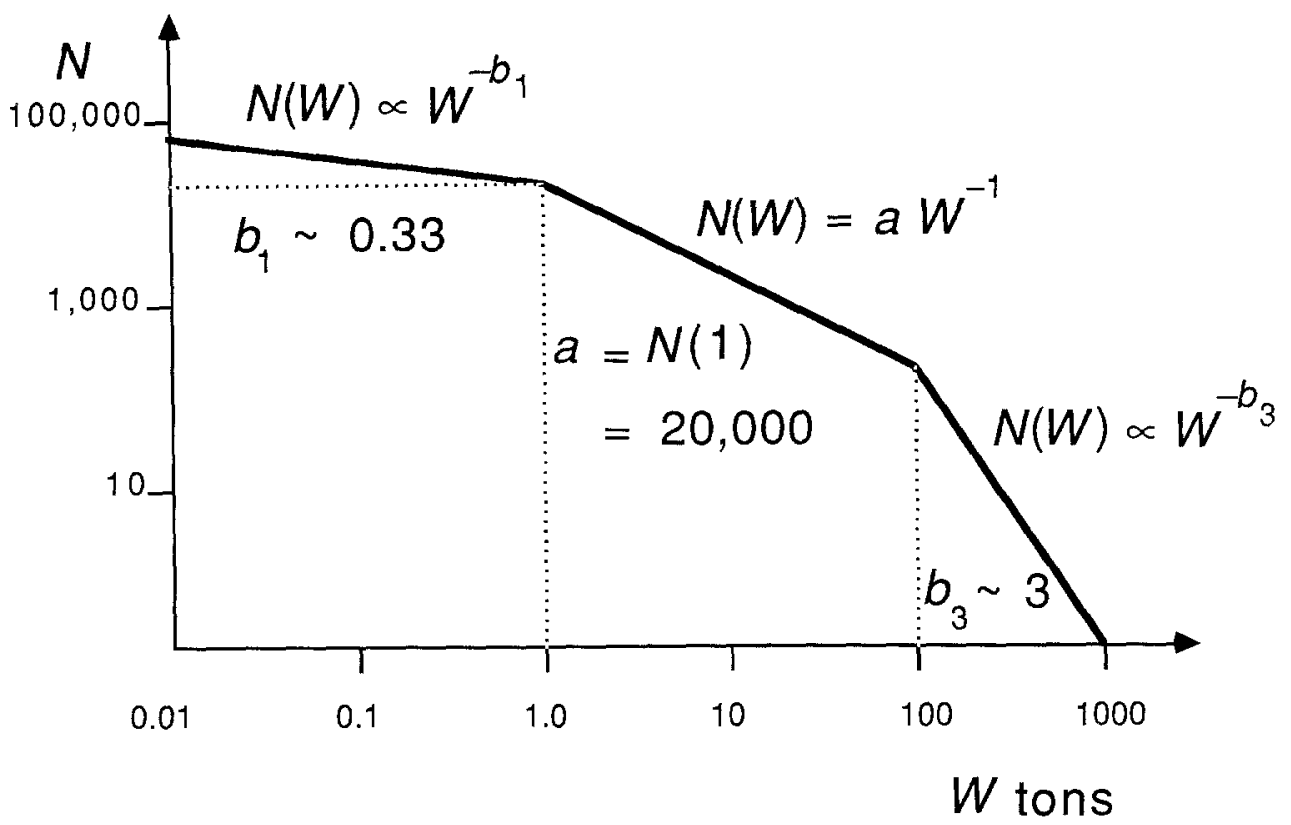

FIG. 12. A fit, by three line segments, to the Vibra-Tech data on cumulative count shown in Figure 10. This is a log-log plot, with a power law $N=a_{i} W^{-b_{i}}$ for each segment $(i=1,2,3)$.

$W_{\max } \rightarrow \infty$ and still get a convergent integral (because $b_{1}<1$ and $b_{3}>1$ ), finding:

$$
\text { total explosive }=N(1)\left(\frac{b_{1}}{1-b_{1}}+2 \log _{e} 10+\frac{b_{3}}{b_{3}-1}\right) .
$$

The three terms here correspond respectively to the totals contributed from explosions smaller than 1 ton, between 1 and 100 tons, and larger than 100 tons. The critical $b$-value of unity (assumed here between 1 and 100 tons) is precisely that which ensures a constant contribution to the total, per decade in $W$. Choosing $b_{1}=0.33, b_{3}=3$, and $N(1)=20,000$, which seem appropriate from Figure 10, equation (2) does give an accurate result (132 kt) for the known total $(135 \mathrm{kt})$. The three separate terms are in the ratio 0.5:4.6:1.5, and the dominant contribution to the total explosive does come from the middle range ( 1 to 100 tons).

We are now in a position to discuss quantitatively the cumulative count for all U.S. explosions, making extrapolations from the Vibra-Tech database and using the known value of 2.04 megatons for total explosive use (see Table 1).

If the U.S. cumulative count is the same shape as that for the Vibra-Tech monitored data, then the scaling factor is constant across all $W$ and is just the ratio of the two totals: 2.04 megatons $/ 135 \mathrm{kt}=15$. It would follow that the two percentages in Table 6 both become $6.5 \%$ and there are about 7500 explosions per year above 50 tons and about 25 above 500 tons ( $b$-value is 3 above 100 tons).

If the U.S. cumulative count shows a higher proportion of large explosions than does the Vibra-Tech data, then we can take an extreme example of such a distribution by assuming that for the decade from 100 to 1000 tons the $b$-value 
is also unity. Neglecting the contribution of small explosions we would find the $a$-value in the power law $N_{U . S}=a W^{-1}$ from the integral (equation 1) for total explosive with $W_{\text {min }}=1$ and $W_{\text {max }}=1000$. It then would follow that there are about 6000 explosions per year above 50 tons and about 600 per year above 500 tons. The big difference from the previous estimate (concerning numbers of very large chemical explosions) is due to continuation of a $b$-value of unity, rather than $b=3$, for $W>100$ tons. However, the difference in numbers of explosions greater than 50 tons is not substantial, and we can have confidence in Table 6 as a summary of conservative estimates.

\section{Conclusions of Blasting Survey and Discussion}

The monitoring data gathered in 1987 by Vibra-Tech were compared with explosive-use totals and geographical distribution from the U.S. Bureau of Mines and to the distribution of mines listed by the Mine Safety and Health Administration. These comparisons indicate that in many respects the monitoring data, which include information on shot sizes, are representative of blasting practices in the United States.

Shots were divided into three categories of small $(<10,000 \mathrm{lb}$, about 5 tons), medium (between 10,000 and 100,000 lb), and large ( $>100,000 \mathrm{lb}$, about 50 tons). We estimate that total shots for 1987 for the medium-shot category are about 10 times more than monitored by Vibra-Tech, and the total for the large-shot category are about 20 times greater. The small-shot category includes underground and construction blasting, and we have not estimated total U.S. shots in this category. These conclusions are summarized in Table 6.

The number of large shots (greater than about 50 tons) corresponds to approximately 30 per day. From information on blasting agents supplied to a limited number of mines known to carry out shots routinely in the range from 100 to 500 tons (see Table 1), we can add that the estimated count of explosions greater than 50 tons would be expected to include at least one per day greater than 200 tons.

If we take the typical shot in the large category as 100 tons, then Table 6 indicates about one megaton a year is used in large chemical explosions in the United States. If the typical medium-sized shot is 20 tons, then about 1.3 megatons are used annually in this category. When added to the annual total explosive for small shots, it is therefore clear that Table 6, with all its uncertainties, errs on the side of over-estimation-because it implies an overall total explosive use that exceeds the two megatons reported by USBM (Table 3 ).

The main point, however, from the perspective of those concerned with nuclear explosion monitoring and the question of discriminating between chemical and nuclear explosions, is that a large industrialized country can be expected to carry out large numbers of chemical explosions. If the concern is with identifying all nuclear explosions down to about $5 \mathrm{kt}$, the intersection with industrial chemical explosions appears manageable if there is a will to take a problem-solving approach to the limited number of evasion scenarios, such as decoupling (U.S. Congress, 1988).

If the concern is with monitoring down to $1 \mathrm{kt}$, i.e., at yield levels low enough that full decoupling becomes technically more feasible (with decoupling factors around 70 at frequencies below the corner frequency), then monitoring would require a threshold of detection low enough that many thousands of chemical explosions would be routinely recorded. In this situation, the key to robust 
methods of discrimination will be an understanding of the signals of ripple-fired explosions, as opposed to single-shot explosions. Amplitudes of regional seismic waves are much reduced by ripple-firing.

Our goal in this paper was to get estimates, where none were available, of the numbers of chemical explosions in the United States and to characterize their size distribution. Further work is needed to characterize the distribution of U.S. explosions greater than 50 tons in size. Work is also needed to obtain chemical explosion statistics for other nuclear weapon states and for countries of concern under the current non-proliferation regime.

\section{ACKNOWLEDGMENTS}

We thank Frederick Smith of the Institute of Makers of Explosives and Anne Coughlin of MSHA for technical advice and Klaus Jacob and Susan Hough for comments on a draft manuscript. This project was supported by the Defense Advanced Research Projects Agency and monitored by the Geophysics Laboratory (later Phillips Laboratory) under Contract No. F19628-88-K-0041. LamontDoherty Geological Observatory Contribution no. 4891.

\section{REFERENCES}

Greenhalgh, S. A. (1980). Effects of delay shooting on the nature of $P$-wave seismograms, Bull. Seism. Soc. Am. 70, 2037-2050.

Greenhalgh, S. A., H. M. Mooney, and C. C. Mosher (1980). The Minnesota Network, Bull. Seism. Soc. Am. 70, 1347-1368.

Hedlin, M. A. H., J. B. Minster, and J. A. Orcutt (1989). The time-frequency characteristics of quarry blasts and calibration explosions in Kazakhstan, USSR, Geophys. J. Int. 99, 109-121.

Kinney, G. F. and K. J. Graham (1985), Explosive Shocks in Air, Springer-Verlag, New York.

Richards, P. G., D. A. Anderson and D. W. Simpson (1991). A Survey of Blasting Activity in the United States (with Appendix on Distribution of Delays), Report No. PL-TR-91-2123, Phillips Laboratory, U.S. Air Force, Massachusetts.

Richards, P. G. and J. Zavales (1990). Seismic discrimination of nuclear explosions, Ann. Rev. Earth Planet Sci. 18, 257-286.

Scholz, C. H. and P. A. Cowie (1990). Determination of total strain from faulting using slip measurements, Nature 346, 837-839.

Smith, A. T. (1989). High-frequency seismic observations and models of chemical explosions: implications for the discrimination of ripple-fired mining blasts, Bull. Seism. Soc. Am. 79, 1089-1110. (Erratum on p. 1671.)

Taylor, S. R., M. D. Denny, E. S. Vergino, and R. E. Glaser (1989). Regional discrimination between NTS explosions and western U.S. earthquakes, Bull. Seism. Soc. Am. 79, 1142-1176.

U. S. Bureau of Mines (1988). Apparent Consumption of Industrial Explosives and Blasting Agents in the United States, 1987, Mineral Industry Surveys, Washington, D.C., $12 \mathrm{pp}$.

U. S. Congress, Office of Technology Assessment (1988). Seismic Verification of Nuclear Testing Treaties; OTA-ISC-361, Washington, D.C., U. S. Government Printing Office.

LAMONT-DOHERTY

Geological Observatory

Palisades, New York 10964

(P.G.R., D.W.S.)
Vibra-Tech EngInefrs, INC.

P.O. Box 577

Hazelton, Pennsyluania 18201-0577

(D.A.A.)

Manuscript received 4 September 1991 